\title{
Artificial neural network techniques for predicting severity of Spodoptera litura (Fabricius) on groundnut
}

\section{Authors Info}

S. Vennila", G. Singh', G. K. Jha², M. S. Rao, H. Panwar' and M. Hegde

${ }^{1}$ Agricultural Knowledge

Management Unit, National

Research Centre for Integrated Pest

Management, New Delhi -110 012,

India

${ }^{2}$ Department of Economics, Indian Agricultural Research Institute, New Delhi-110 012, India

${ }^{3}$ Division of Crop Sciences, Central Research Institute for Dryland Agriculture, Hyderabad- 500059 , India

${ }^{4}$ Department of Entomology, University of Agricultural Sciences, Dharwad-580 005, India

${ }^{*}$ Corresponding Author Email : svennila96@gmail.com

Key words

Groundnut,

Neural network,

Sensitivity analysis,

Spodoptera litura,

Weather variables

Publication Info

Paper received: 19.09 .2015

Revised received: 29.02 .2016

Re-revised received: 29.06 .2016

Accepted: 13.07 .2016

\section{Abstract}

Aim : Approaches to modelling pest populations range from simple empirical models to advanced soft computing techniques that have advantages as well as limitations.A comparative analyses of modelling approaches result in selection of betterpest forecast model with a higher prediction accuracy.

Methodology : Artificial neural network (ANN) techniques viz., multi-layer perceptron neural network (MLP-NN) and polynomial neural networks (PNN) were used along with the multiple and polynomial regressions to predict the moth population of tobacco caterpillar Spodoptera litura (Fabricius) in groundnut cropping system. S. litura pheromone trap catch and weather data of twenty five years (1990-2014) for kharif season (26 to 44 standard meteorological weeks (SMW)) was used for predictive modelling. The weekly male moth catches of $S$. litura (numbers/trap/week) during maximum severity period (34 SMW) was modelled using weather variables viz., maximum and minimum temperature $\left({ }^{\circ} \mathrm{C}\right)$, rainfall $(\mathrm{mm})$, morning and evening relative humidity (\%) lagged by two weeks. The performance of the models was evaluated using coefficient of determination $\left(\mathrm{R}^{2}\right)$, root mean square error (RMSE) and mean absolute percentage error (MAPE) estimates.

Results : The study clearly demonstrated the superiority of MLP-NN $\left(R^{2}: 0.89\right)$ over all other models for predicting the peak severity of $S$. litura. Sensitivity analysis of MLP-NN model indicated that the maximum temperature lagged by two weeks and evening relative humidity of the previous week was two most important factors influencing the peak population of S.litura. Validation also demonstrated the effectiveness of MLP-NN followed by PNN in dealing with non-linear relation between $S$. litura population and weather variables.

Interpretation : All model equations developed in the present study can be used to predict $S$. litura peak (34 SMW) in conjunction with weather of 32 and 33 SMW during kharif season, and in issuing need based advisories for its effective management on groundnut.

MLP-NN $(6,6,1)$ predicting Spodoptera litura population

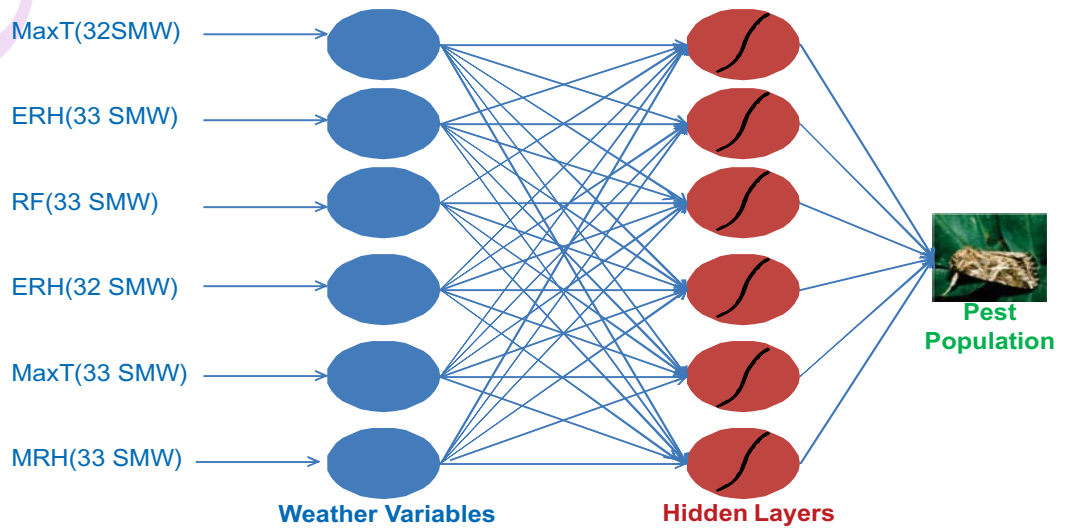




\section{Introduction}

Groundnut is grown in 25.42 million ha area worldwide with total production of 45.65 million tons, and an average yield of $1796 \mathrm{kgha}^{-1}$. India cultivates groundnut in about 43 and $20 \%$ of Asian and global area, respectively with a corresponding production estimate of 25 and $16 \%$ (FAOSTAT, 2014). India is the second largest groundnut producer $(9.67 \mathrm{mt})$ after China (17.02 $\mathrm{mt}$ ) and contributes to more than one third of total oilseed production (32.88 mt) in the country (Anonymous, 2014a). Groundnut productivity in India (1804 kg ha') however is low as compared to USA (4496 kg ha-1) and China (3660 kg ha-1) ((FAOSTAT, 2014). The main reason for low productivity is that the crop is grown mostly in small farm holdings under rainfed conditions with limited inputs apart from yield loss caused by plethora of insect pests and diseases (Anonymous, 2014b). Losses due to insect pests in Indian agriculture have been estimated from time to time (Dhaliwal et al., 2010), and it ranges from 10 to $30 \%$ annually depending upon the severity of pest attack. The tobacco caterpillar or Spodoptera litura (Fabricius) is one of the major insect-pests that caused defoliation of groundnut crop with an estimated yield loss of $15-30 \%$ during its occurrence between March and October.

Gregarious and solitary feeding by early and late S. litura larval stages reduces the leaf area which in turn limits the yield potential of crop by retarding photosynthesis. Understanding and managing the effects of agricultural pests and diseases are major challenges in the context of climate change as the crop and its pests are sensitive to prevalent weather and to the extreme weather events. Analysis of population dynamics of $S$. litura accounting for inter seasonal variability in relation to climatic variations through appropriate modeling tools provides an opportunity for prediction of its occurrence and better management for realization of increased production and productivity.

Several researchers have made significant contribution to weather based pest population dynamics modelling in agricultural crops using linear, as well as nonlinear techniques in the Indian context (Agrawal and Mehta, 2007). These studies have utilised traditional regression approach with weather indices based regression model. The complexity of dependencies of pest population on weather variables and their nonlinear relationship necessitates the use of soft computing techniques for forewarning purposes. These techniques have capability of human brain in terms of biological neurons to solve complex or non-linear pattern among input and output data sets. Neural network approaches have been successfully applied in a number of diverse fields including insect-pest management, in general and in modelling pest population dynamics, in particular (Laxmi and Kumar, 2011; Yang et al., 2009; Chakraborty et al., 2004; Gaudart et al., 2004). Multilayer perceptron neural network (MLP-
$\mathrm{NN}$ ) is one of the commonly used techniques for modelling pest population dynamics.

Group method of data handling (GMDH) is a popular tool to express complex nature of input- output dependencies. GMDH based neural network composed of self-organizing active neurons have been found to be very effective in accurate and less labour-intensive forecasts over the traditional time-series and regression-based models (Srinivasan, 2008). The polynomial neural network (PNN) based on GMDH algorithm have fewer nodes as compared to MLP-NN, and the nodes are more flexible (Bishop, 2006).Very few studies have been conducted for modelling the pest population dynamics using polynomial neural network or GMDH type neural network and MLP- structure based on weather variables. The main objective of the present work was to investigate the potential of soft computing techniques (PNN and ANN) as compared to traditional statistical regression model predicting peak occurrence of $\mathrm{S}$. litura of groundnut cropping system using weather variables.

\section{Materials and Methods}

Data base developed on the population dynamics studies of $S$. litura carried out over a period of twenty five years (19902014) for the kharif season (26 to 44 standard meteorological weeks (SMWs) in groundnut cropping system and the meteorological data recorded at the University of Agricultural Sciences, Dharwad $\left(15^{\circ} 21^{\prime} \mathrm{N}\right.$ to $\left.74^{\circ} 57^{\prime} \mathrm{E}\right)$ formed the basis for the analysis. The unit of measurement of population of $S$. litura was weekly male moth catches caught in pheromone traps in groundnut fields deployed @5 ha ${ }^{-1}$ for monitoring the pest activity. Data for weather parameters viz., maximum temperature $\left(\operatorname{MaxT},{ }^{\circ} \mathrm{C}\right)$, minimum temperature $\left(\operatorname{Min} T,{ }^{\circ} \mathrm{C}\right)$, rainfall $(\mathrm{RF}, \mathrm{mm})$, and morning and evening relative humidity (MRH and ERH in \%) corresponding to the crop seasons with respect of study years were gathered from the meteorological observatory of the same location. All the weather and $S$. litura variables were preprocessed in view of their heterogeneous units of measurement. Each variable was transformed over the range of -1 to 1 using transformation prior to the training process as given below

$$
y_{i j}=\frac{x_{i j}-\bar{x}_{j}}{\max \left(x_{i j}\right)-\bar{x}_{j}}
$$

where, $y_{i j}$ is the element of $i^{\text {th }}$ row and $j^{\text {th }}$ column of the transformed data matrix $Y$; $x_{i j}$ is the element of $i^{\text {th }}$ row and $j^{\text {th }}$ column in original data matrix $X ; X_{j}$ is the mean of $j^{\text {th }}$ column during the period under study. Mean incidence and maximum period of severity of $S$. litura with respect to seasons was calculated in order to find the pest status and most common SMW with maximum severity for which prediction would be done, respectively. The frequencies for the periods of maximum occurrence were ordered to find the SMW of peak severity. In 
order to model the population occurrence of $S$. litura at its maximum severity, wherein the peak occurrence of $S$. litura was found to be 34 SMW, multiple linear regression (MLR), polynomial regression (PLR), artificial neural network (ANN) and polynomial neural network (PNN) techniques were used considering the weather lag by two weeks corresponding to that of the population of S. litura during 34 SMW of 25 seasons. Stepwise multiple regression procedure (Montgomery et al., 2003) was employed to determine the significant weather variable(s) and their extent of contribution in determining $S$. litura catches using both MLR and PLR. While MLR used individual weather variables as inputs, for polynomial regression models higher degree terms of the weather variables and also the possible interactions amongst weather variables were taken. The general forms of used models are given below:

Let, S. litura (y) occurrence be affected by the weather variables, and then the multiple linear regression (MLR) model is defined as:

$$
y_{i}=\beta_{0}+\beta_{1} x_{1}+\beta_{2} x_{2}+\ldots+\beta_{p} x_{p}+\varepsilon_{i}
$$

where, $\beta_{i}$ is regression coefficient; $x_{i}$ is weather variable and $\varepsilon$ is error term $\mathrm{i}=1,2, \ldots \mathrm{p}$.

The general form of the polynomial regression can be written as:

$$
y_{i}=\beta_{0}+\sum_{i=1}^{p} \beta_{1} x_{1}+\sum_{i=1}^{p} \beta_{i} x_{i}^{2}+\ldots .+\sum_{i=1}^{p} \beta_{i} x_{i}^{k}+\sum_{i=1}^{p} \sum_{\substack{j \\ i \neq 1}}^{p} \beta_{i j} x_{i} x_{j}+\varepsilon_{i}
$$

where, $\mathrm{k}$ is degree of the polynomial.

The functional form of polynomial neural network (PNN), fundamentally based on group method of data handling procedure is given by

$$
y_{i}=\alpha+\sum_{i=1}^{p} \beta_{i} x_{i}+\sum_{i=1}^{p} \sum_{j=1}^{p} y_{i j} x_{i} x_{j}+\sum_{i=1}^{p} \sum_{j=1}^{p} \sum_{k=1}^{p} \delta_{i j k} x_{i} x_{j} x_{k}+\ldots+\varepsilon_{i}
$$

where, $x_{1}, x_{2} \ldots \ldots . x_{p}$ are $p$ input variables and $y$ is output variable.

The general form of MLP-NN output produced by a network consisting of $p$ input nodes, $q$ hidden nodes and one output node (o) is written as:

$$
y_{i}=g\left\{\alpha_{0}+\sum_{k=1}^{p} \alpha_{k} f\left(\beta_{0 k}+\sum_{j=1}^{p} \beta_{j k} x_{j}\right)\right\} ; i=1,2, \ldots \ldots, n
$$

where, $y_{i}$ denotes the pest population in $\mathrm{ith}^{\text {th }}$ year; $f$ and $g$ denote the activation function at hidden and output layer, respectively. $\beta_{j k}$ is the weight attached to the connection between $j^{\text {th }}$ input node and the $k^{\text {th }}$ node of hidden layer, $\beta_{0 k}$ is the bias at the input layer, $\alpha_{k}$ is the weight attached to the connection from $k^{\text {th }}$ hidden node to the output node and is the bias at the hidden layer. The network was trained using Levenberg-Marquartelt algorithm considering its fast convergence and high efficiency. STATISTICA ${ }^{\circledR}$ Neural Network version 6.1 was used for the MLP-NN model development, while GMDH Shell ${ }^{\circledR}$ were used for estimating the polynomial neural network.

The forecasting performance of the all the fitted models viz., MLR, PLR, PNN and MLP-NN were evaluated on the basis of coefficient of determination $\left(R^{2}\right)$, root mean square error (RMSE) and mean absolute percentage error (MAPE). These statistical measures are defined as:

$$
\begin{aligned}
& R^{2}=1-\frac{\sum_{i=1}^{n}\left(y_{i}-\widehat{y}_{1}\right)^{2}}{\sum_{i=1}^{n}\left(y_{i}-\bar{y}^{2}\right.} \\
& \text { RMSE }=\sqrt{\frac{\sum_{i=1}^{n}\left(y_{i}-\widehat{y}_{1}\right)^{2}}{n}} \\
& \text { MAPE }=\frac{\sum_{i=1}^{n}\left|\frac{y_{i}-\widehat{y}_{1}}{y_{i}}\right|}{n}
\end{aligned}
$$

where, $y_{i}$ and $\hat{y}_{1}$ are the observed and predicted adult moth population in $i^{\text {th }}$ year, $\bar{y}$ is the average adult moth population and $n$ is the number of observations. Sensitivity analysis was carried out to evaluate the relative contribution of each weather parameter as input variable to model peak occurrence of $S$. litura, as target variable. Since model was being developed for peak severity week (i.e. $34 \mathrm{SMW}$ ), number of observations were same as the number of years $(n=25)$.

\section{Results and Discussion}

$S$. litura male moths in pheromone traps of groundnut cropping system were observed from the last week of June (26 SMW) to the first week of November (44 SMW) with five (19972000 and 2002) and two (2005 and 2014) seasons having one and two weeks of delayed onset, respectively. The delayed onset with respect to seasons 2001 and 2013 was three and four weeks. Cessation of moth catches too was as early by six weeks (1994) to just one week (1996, 2004, 2005 and 2009). The common period of occurrence of $S$. litura was between SMW 30-38 over all seasons. The mean population level among the seasons indicated 11 and 331 moths/trap/week to be the lowest and highest seasonal occurrence of S. litura during 2001 and 2010, respectively. Prasad et al. (2013) while analysing the population of S. litura for their outbreaks in the soybean cropping system at Maharashtra too had reported similar inter-annual variability of moth catches. Also, it has been reported in the context of climate change that the extreme events that are unseasonal affected the population dynamics drastically over the gradual changes of climatic variability (Anonymous, 2014c). Although $27^{\circ} \mathrm{C}$ was found to be ideal for growth of $S$. litura, increasing developmental rate was noticed up to $30^{\circ} \mathrm{C}$ in a study that predicted $\mathrm{S}$. litura for future periods of climate change (Rao et al., 2014) justifying the 
Table1 : Mean and maximum population of $S$. litura during kharif

\begin{tabular}{llllll}
\hline Season & \multicolumn{2}{c}{ S. litura(No./trap/week) } & & Year & \multicolumn{2}{c}{ S. litura(No./trap/week) } \\
\cline { 2 - 3 } & Maximum & Mean & & Maximum & Mean \\
\hline 1990 & $664(30)$ & 252 & 2003 & $197(33)$ & 48 \\
1991 & $238(32)$ & 80 & 2004 & $764(36)$ & 168 \\
1992 & $343(36)$ & 105 & 2005 & $561(34)$ & 189 \\
1993 & $462(38)$ & 173 & 2006 & $884(38)$ & 311 \\
1994 & $482(27)$ & 148 & 2007 & $839(34)$ & 200 \\
1995 & $311(34)$ & 97 & 2008 & $168(36)$ & 96 \\
1996 & $601(27)$ & 228 & 2009 & $1376(34)$ & 302 \\
1997 & $315(29)$ & 122 & 2010 & $884(32)$ & 331 \\
1998 & $951(28)$ & 275 & 2011 & $894(35)$ & 206 \\
1999 & $176(39)$ & 2012 & $648(34)$ & 196 \\
2000 & $415(36)$ & 88 & 2013 & $188(40)$ & 38 \\
2001 & $34(36)$ & 11 & 2014 & $43(38)$ & 13 \\
2002 & $154(29)$ & 49 & & & \\
\hline
\end{tabular}

Note: Figures in parenthesis denote SMW having peak S. litura during the season

Table 2 : Descriptive and correlation statistics of $S$. litura population with weather variables

\begin{tabular}{|c|c|c|c|c|c|c|c|c|}
\hline SMW & Variables & Minimum & Maximum & Mean & SE & SD & CV & $\begin{array}{l}\text { Correlation } \\
\text { coefficient with } \\
\text { S. litura" }\end{array}$ \\
\hline \multirow[t]{6}{*}{34} & $\operatorname{MaxT}\left({ }^{\circ} \mathrm{C}\right)$ & 25.00 & 30.56 & 27.22 & 0.28 & 1.41 & 5.19 & 0.145 \\
\hline & $\operatorname{MinT}\left({ }^{\circ} \mathrm{C}\right)$ & 18.16 & 21.67 & 20.28 & 0.14 & 0.68 & 3.37 & 0.232 \\
\hline & $\mathrm{MRH}(\%)$ & 85.71 & 98.43 & 91.64 & 0.56 & 2.80 & 3.06 & 0.177 \\
\hline & ERH(\%) & 59.57 & 94.00 & 78.15 & 1.76 & 8.78 & 11.23 & -0.116 \\
\hline & $\mathrm{RF}(\mathrm{mm})$ & 0.00 & 95.20 & 17.47 & 4.32 & 21.60 & 123.67 & 0.230 \\
\hline & S. litura ${ }^{\#}$ & 4.00 & 1376.00 & 322.00 & 64.44 & 322.22 & 100.07 & 1.000 \\
\hline \multirow[t]{6}{*}{32} & $\operatorname{MaxT}\left({ }^{\circ} \mathrm{C}\right)$ & 24.16 & 28.81 & 26.57 & 0.26 & 1.29 & 4.87 & $0.466^{*}$ \\
\hline & $\operatorname{MinT}\left({ }^{\circ} \mathrm{C}\right)$ & 19.47 & 21.38 & 20.48 & 0.11 & 0.54 & 2.66 & 0.214 \\
\hline & $\mathrm{MRH}(\%)$ & 84.86 & 96.57 & 92.35 & 0.58 & 2.90 & 3.14 & -0.072 \\
\hline & $\mathrm{ERH}(\%)$ & 64.29 & 90.86 & 80.57 & 1.49 & 7.47 & 9.27 & $-0.495^{\star}$ \\
\hline & $\mathrm{RF}(\mathrm{mm})$ & 0.00 & 127.00 & 29.67 & 6.19 & 30.96 & 104.36 & -0.203 \\
\hline & S. litura\# & 2.00 & 884.00 & 214.90 & 51.87 & 259.35 & 120.69 & $0.586^{\star *}$ \\
\hline \multirow[t]{6}{*}{33} & $\operatorname{MaxT}\left({ }^{\circ} \mathrm{C}\right)$ & 24.30 & 28.91 & 26.79 & 0.28 & 1.40 & 5.24 & $0.448^{*}$ \\
\hline & $\operatorname{MinT}\left({ }^{\circ} \mathrm{C}\right)$ & 19.84 & 21.21 & 20.59 & 0.07 & 0.35 & 1.70 & 0.295 \\
\hline & $\mathrm{MRH}(\%)$ & 77.14 & 99.29 & 91.30 & 0.77 & 3.85 & 4.22 & 0.075 \\
\hline & $\mathrm{ERH}(\%)$ & 62.00 & 92.43 & 79.30 & 1.51 & 7.53 & 9.49 & -0.272 \\
\hline & $\mathrm{RF}(\mathrm{mm})$ & 1.00 & 64.60 & 19.98 & 3.82 & 19.11 & 95.64 & -0.016 \\
\hline & S. litura\# & 4.00 & 1032.00 & 247.94 & 51.59 & 257.95 & 104.04 & $0.815^{\star *}$ \\
\hline
\end{tabular}

*: Significant at $P \leq 0.05 ;$ **: Significant at $P \leq 0.01 ; *$ : S. litura moths (No./trap/week)

observed inter seasonal variations of moth catches. Analysis of the frequencies of SMWs having maximum population level of $S$. litura indicated a maximum of six seasons having 34 SMW as their period of peak followed by five seasons having 36 SMW. Even the highest population of 1376 moths caught per trap per week during 2009 across seasons and SMWs coincided with the 34 SMW (Table 1).

Fig. 1 shows seasonal weather vis a vis mean and maximum $S$. litura moth population occurrence over seasons with respect to SMWs of kharif season. Both the mean, as well as maximum population dynamic plots based on the SMWs along the season over years showed 34 SMW as the period of peak or maximum severity. The descriptive statistics for weather factors viz., $\operatorname{MaxT}\left({ }^{\circ} \mathrm{C}\right), \operatorname{MinT}\left({ }^{\circ} \mathrm{C}\right), \operatorname{MRH}(\%), \operatorname{ERH}(\%)$ and $\operatorname{RF}(\mathrm{mm})$, and $S$. litura moth catches with respect to the period of peak severity (34 SMW), and for the two lag weeks (33 and 32 SMWs) in addition to the coefficients between moth population of 34 SMW with weather of concurrent and two lag weeks (33 and 32 SMW) used in modelling are given in Table 2 . While weather variables 
$\sim \operatorname{Max} T\left({ }^{\circ} \mathrm{C}\right)$

$\longrightarrow$ RF total (mm)
$-\operatorname{Min} \mathrm{T}\left({ }^{\circ} \mathrm{C}\right)$

$\longrightarrow$ S. litura (Mean)
- MRH $(\%)$

- S. litura (Max.)

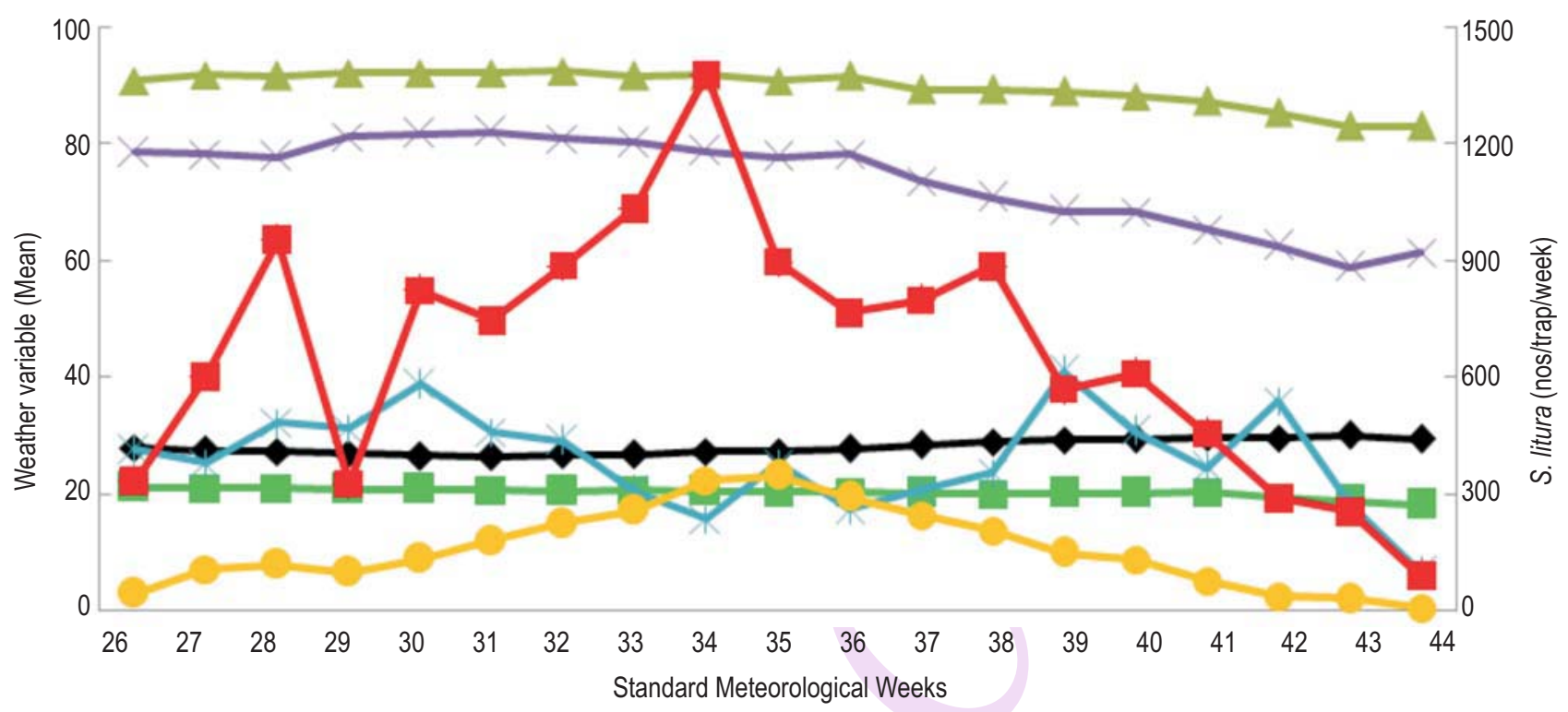

Fig. 1 : Mean and maximum of $S$. litura vis a vis weather variables

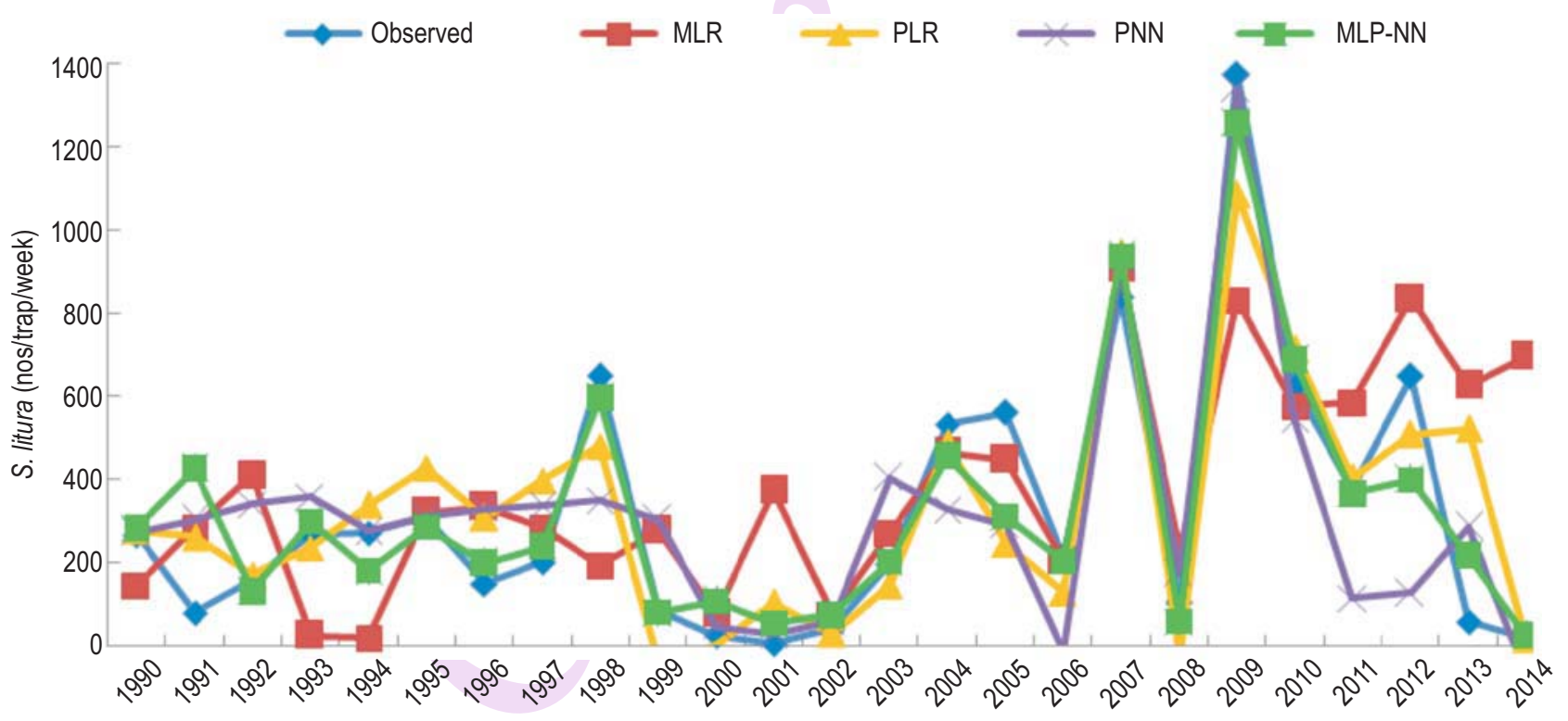

Fig. 2 : Predicted versus observed S. litura peak severity using MLR, PLR, PNN and MLP-NN models

MinT followed by RH accounted for less variations; MaxT, RF and $S$. litura showed maximum variability. The $S$. litura - weather relations for $34 \mathrm{SMW}$ was not insignificant. However, the MaxT of both the lag weeks (33 and 32 SMW) showed positive influence on S. litura. ERH of 32 SMW showed negative relation with peak severity of $S$. litura. It was also to be noted that the relation between population level of $S$. litura during the week of maximum severity (34 SMW) and the immediate preceding week (33 SMW) was greater $\left(r=0.82^{* *} ; p<0.01\right)$ than prior to two weeks (32 SMW) $\left(r=0.59^{* *} ; p<0.01\right)$. Although significant influence of different weather factors of the concurrent week on $S$. litura was reported (Rudraswamy et al., 2006) such a relation was absent in the current study. The convergence of variability for pest and weather variables on account of many (25) seasons rather than single or 
Table 3 : Error statistics for prediction models as a measure of their predictive performance

\begin{tabular}{llll}
\hline Model & $\mathbf{R}^{2}$ & RMSE & MAPE \\
\hline MLR & 0.5227 & 0.2105 & 1.1453 \\
PLR & 0.8175 & 0.1301 & 0.7448 \\
PNN $(6,2,2)$ & 0.7384 & 0.1558 & 0.9006 \\
MLP-NN $(6,6,1)$ & 0.8883 & 0.1018 & 0.3964 \\
\hline
\end{tabular}

limited (2-8) seasons considered for model development could be a reason for the observed difference.

The moth population of S. litura at its peak (34 SMW) predicted by multiple and polynomial linear regression models is as follows:

$\widehat{Y}_{\text {MLR }}=0.326 \mathrm{MRH}_{32}-0.411 \mathrm{ERH}_{32}\left(\mathrm{R}^{2}=0.52\right)$

$\widehat{Y}_{\text {PLR }}=0.379 \operatorname{MaxT}_{32}+0.200 \mathrm{MRH}_{32}-0.434 \operatorname{Max}_{33} \mathrm{ERH}_{32}$

$+0.308 \operatorname{Max}_{33} \mathrm{ERH}_{33}-0.399 \mathrm{MRH}_{32} \mathrm{RF}_{33}\left(R^{2}=0.82\right)$

where, $M_{R 2} H_{32}$ denotes the morning relative humidity of $32 \mathrm{SMW}$ and so on for other weather variables. The polynomial regression model was attempted with quadratic, cubic degree terms of weather variables along with their interactions. The square and cubic terms were not found statistically significant for predicting the peak severity. The coefficient of determination $\left(R^{2}\right)$ revealed that the multiple linear regression model explained $52 \%$ of variations due to weather variables. On the other hand, the polynomial regression model that considers the interaction effects of weather variables improved the prediction by $30 \%$ over $M L R$. The low prediction ability of MLR with respect to $S$. litura on groundnut was also reported by Rao et al. (2015) for Dharwad location.

The polynomial neural network model developed using GMDH algorithm considered the weather variables as input and $S$. litura population as output; wherein prediction errors were recorded with varying hidden layers and neuron complexity. Based on the direct mapping of relationship among input and output variables of system PNN analytical technique built a selforganizing model of higher-order degree polynomial amongst the independent variables heuristically different from the traditional regression algorithm based on solid theoretical foundation in linear dependence of input variables. Since, the PNN algorithm results in systematic and autonomous optimal complex model by performing both variable and structure identification (Lemke and Mueller, 2003) procedure, its application was made in the present study. The resulted prediction model had 2 layers, 2 units and two fold validation strategies. The PNN model for prediction is as follows:

$\widehat{\mathrm{P}}_{\text {PNN }}=6.193 \mathrm{~N} 26 \mathrm{~N} 33-4.080 \mathrm{~N} 33^{2}$
$\mathrm{N} 26=-0.263 \mathrm{ERH}_{32}+0.108 \mathrm{ERH}_{32}{ }^{2}$

$\mathrm{N} 33=0.310 \mathrm{MaxT}_{32}-0.259 \mathrm{MinT}_{32}{ }^{2}$

where; N26 and N33 were selected as the estimators for predicting $S$. litura because they had minimum RMSE among several output layers. While N26 layer had relative humidity, N33 included maximum and minimum temperature with weather variables in both the cases corresponding to the previous two weeks.

A typical MLP-NN architecture consists of an input layer that accepts external information namely weather variables in this case, one or more hidden layers that provide non-linearity to the model and an output layer that provides the target value. Each layer contains one or more nodes. The input signal propagates through the network in a forward direction ensuring that the network outputs are calculated as explicit functions of the inputs and their weights. Neural network with a single hidden layer and sufficiently large number of neurons approximates any nonlinear function (Jha and Sinha, 2014). Hence, neural network model with single hidden layer was designed in the present study and it signified a multilayer perceptron network model with 6 input variables, 6 neurons in the hidden layers with one output variable. While the trained ANN models were implemented for predicting pest population of $S$. litura, the hyperbolic tangent function was used as an activation function for mapping the non-linear pattern of pest population.

Considering the non-linear nature of $S$. litura and weather variables, and the availability of plethora of approaches for modelling, it becomes imperative to compare the performance of models before utilising them for prediction purposes. The polynomial neural network model which embodies the characteristics of both GMDH and MLP is better suited for understanding the relationship between $S$. litura with weather variables, and MLP-NN is more suitable for predicting the population. GMDH algorithm has individual advantage over regression procedures, since it eliminates the variables that do not correlate highly with the target variable in addition to the fewer computations involved. Table 3 displays the forecast performance for each prediction model in terms of error measures viz.,, RMSE, and MAPE, wherein the highest $R^{2}$ and lowest RMSE and MAPE values represent highest accuracy of prediction. Performance measures clearly demonstrated the effectiveness of neural network based model in dealing with the non-linear relation between the insect population and the meteorological factors. Also, all the non-linear models viz., PLR, PNN and MLP-NN had stronger degree of fitting as inferred through higher $R^{2}$ and comparatively lower RMSE over the MLR model. The MLP-NN performed slightly better as compared to other two network models. Bianconi et al. (2010) and Shankar et al. (2007) have also revealed the importance of neural network model for predicting pest population in relation to weather variables. The better 
Table 4 : Sensitivity of the weather variables in the prediction models

\begin{tabular}{ll}
\hline Model & Input variables along their order of contribution \\
\hline MLR & $\operatorname{ERH}_{32}(<0.001), \mathrm{MRH}_{32}(0.006)$ \\
PLR & $\operatorname{MaxT}_{33} \mathrm{ERH}_{32}(<0.001), \operatorname{MaxT}_{32}(<0.001), \mathrm{MRH}_{32}(0.028), \operatorname{MaxT}_{33} \mathrm{ERH}_{33}(0.003), \mathrm{MRH}_{32} \mathrm{RF}_{33}(0.015)$ \\
$\mathrm{PNN}(6,2,2)$ & $\operatorname{MaxT}_{32}(9), \mathrm{RF}_{33}(7), \mathrm{MRH}_{32}(7), \operatorname{MinT}_{32}(6), \mathrm{ERH}_{32}(6), \operatorname{MaxT}_{33}(5), \operatorname{MinT}_{33}(5), \mathrm{MRH}_{33}(4), \mathrm{ERH}_{33}(4), \mathrm{RF}_{32}(1)$ \\
$\mathrm{MLP}(6,6,1)$ & $\operatorname{MaxT}_{32}(3.425), \mathrm{ERH}_{33}(2.600), \mathrm{RF}_{33}(2.342), \mathrm{ERH}_{32}(1.877), \operatorname{MaxT}_{33}(1.850), \mathrm{MRH}_{33}(1.474)$ \\
\hline
\end{tabular}

Note: Figures in parenthesis are the $\mathrm{p}$-values for the regression, sensitivity ratio for MLP network and the numbers of usage for PNN

predictive capability of MLP-NN was due to its higher sensitivity in identifying the complex non-linear nature of pest population. The plots of the predicted as against the observed peak population of $S$. litura in respect of the different seasons indicated better match of the MLP-NN over other models (Fig.2).

Table 4 presents the sensitivity measure of input variables for the prediction models used in the present study. Sensitivity analysis of the developed model provides information about relative importance of weather variables entered in the neural network model. Sensitivity analysis yields a ratio of the network error with a given input included as well as omitted. It also shows the rank of these ratios for each input in the order of importance. The maximum temperature and evening $\mathrm{RH}$ prior to two weeks (32 SMW), and maximum temperature, morning and evening $\mathrm{RH}$ and RF prior to one week (33 SMW) were the influencing factors of peak moth population of $S$. litura on groundnut based on MLP-NN model.

The importance of weather variables of the lag weeks influencing the peak severity of $S$. litura was recognised through the current study. MLP-NN approach was found to be robust over MLR, PLR and PNN models for forecasting the $S$. litura peak population at 34 SMW for Dharwad in groundnut cropping systems. The developed forecast system included as a tool for $S$. litura pest management in groundnut could result in a sophisticated and scientifically based area wide implementation of integrated pest management besides serving as a template for forecast of other crop pests and locations.

\section{Acknowledgment}

Authors gratefully acknowledge the funding of National Innovations in Climate Resilient Agriculture (NICRA) for undertaking the current study. As the long term data on pest and weather involves many unknown contributors over time, their efforts are placed on record with sincere appreciations.

\section{References}

Agrawal, R. and S.C. Mehta: Weather based forecasting of crop yields, pests and diseases - IASRI Models. J. Indian Soc. Agric. Statist., 61, 255-263 (2007).

Anonymous: Agricultural Statistics at a Glance. Directorate of Economics and Statistics, Department of Agriculture and Cooperation,
Ministry of Agriculture, Government of India (2014a).

Anonymous: Status paper on oilseeds. Department of Agriculture and Cooperation, Ministry of Agriculture, Government of India (available at: http://nmoop.gov.in/Publication/Status_Paper.pdf) (2014b).

Anonymous: Pest dynamics in relation to climate change. Annual Report 2013-14. National Centre for Integrated Pest Management, New Delhi. p. 61 (2014c).

Bianconi, A., C.J. Von Zuben, A.B.S. Serapiao and J.S. Govone: Artificial neural networks: A novel approach to analyzing the nutritional ecology of a blowfly species, Chrysomya megacephala. J. Insect Sci., 10 (2010).

Bishop, C.M.: Pattern Recognition and Machine Learning: Springer (2006).

Chakraborty, S., R. Ghos., M. Ghosh, C.D. Fernandes and M.J. Charchar: Weather-based prediction of anthracnose severity using artificial neural network models. Plant Pathol., 53, 375-386 (2004).

Dhaliwal, G.S., V. Jindal and A.K. Dhawan: Insect pest problems and crop losses: changing trends. Indian J. Ecol., 37, 1-7 (2010).

FAOSTAT.:http://faostat.fao.org./site/567/default.aspx\#ancor(2014).

Gaudart, J., B. Giusiano and L. Huiart: Comparison of the performance of multi-layer perceptron and linear regression for epidemiological data. Comput. Stat. DataAnal., 44, 47-70 (2004).

Jha, G.K. and K. Sinha: Time-delay neural networks for time series prediction: an application to the monthly wholesale price of oilseeds in India. Neural Comput. Appl., 24, 563-571 (2014).

Laxmi, R.R. and A. Kumar: Forecasting of powdery mildew in mustard (Brassica juncea) crop using artificial neural networks approach. Indian J. Agric. Sci, 81, 855-60 (2011).

Lemke, F. and J.A. Mueller: Medical data analysis using self-organizing data mining technologies. Syst. Anal. Model. Simul., 10, 13991408 (2003).

Montgomery, D.C., E.A. Peck and G.G. Vining: Introduction to linear regression analysis. John Wiley and Sons. Inc., New York (2003).

Prasad, Y.G., M. Gyathri, M. Prabhakar, P. Jeyakumar, S. Vennila, A.V.M. Rao, I. Subba Rao, K.V. Bhaskara Rao, G. Rao Ramachandra and V.U.M. Rao: Population dynamics of Spodoptera litura outbreak on soybean vis a vis rainfall events. J. Agric. Meteorol., 15, 37-40 (2013).

Rao, M.S., P. Swathi, D. Manimanjari, A.C.R. Rao and M. Maheswari: Effect of climate change on Spodoptera litura Fab. on peanut:A life table approach. Crop Protec., 66,98-106 (2014).

Rao, M.S., D. Manimanjari, A.C.R. Rao and M. Maheswari: Prediction of pest scenarios of Spodoptera litura Fab. in peanut growing areas of India during future climate change. Natt. Acad. Sci. Lett., 38, 465-468 (2015).

Rudraswamy, S.M., S.N. Megeri and B.S. Nandihalli: Influence of 
weather parameters on moth catches of Spodoptera litura (F.). Karnataka J.Agric. Sci.,19,138-139, (2006).

Shankar, D.R., A. Kodali, P. Beerla and D.V.S.M. Nimai: Neural Networks in Cultivation. Fourth International Conference on Information Technology (ITNG'07), pp. 255-260 (2007).

Srinivasan, D.: Energy demand prediction using GMDH networks.
Neurocomputing, 72, 625-629 (2008).

Yang, L.N., L. Peng, L.M. Zhang, L.L. Zhang and S.S. Yang: A prediction model for population occurrence of paddy stem borer (Scirpophaga incertulas), based on back propagation artificial neural network and principal component analysis. Comput. Elect. Agri., 68, 200-206 (2009). 